\title{
Is there an unmet medical need for palliative care services in Germany? Incidence, prevalence, and 1-year all-cause mortality of palliative care sensitive conditions: real-world evidence based on German claims data
}

\author{
H. Gothe ${ }^{1,2,3}$ (D) - C. Brinkmann ${ }^{1} \cdot$ N. Schmedt ${ }^{4}$ - J. Walker ${ }^{4} \cdot$ C. Ohlmeier $^{1}$
}

Received: 2 February 2020 / Accepted: 16 May 2020 / Published online: 1 July 2020

(C) The Author(s) 2020

\begin{abstract} Germany who received palliative care treatment. cause mortality.

All authors contributed to the study conception and design. Material preparation, data collection, and analysis were performed by Carolin Brinkmann, Holger Gothe Christoph Ohlmeier, Niklas Schmedt and Jochen Walker. The first draft of the manuscript was written by Carolin Brinkmann, Holger Gothe, and Christoph Ohlmeier. All authors commented on previous versions of the manuscript. All authors read and approved the final manuscript.
\end{abstract}

Aim To characterize palliative care patients, to estimate the incidence, prevalence, and 1-year all-cause mortality in patients in

Subject and methods The study analyzed the InGef Research Database, which covers 4 million people insured in German statutory health insurance companies. Specific outpatient and inpatient reimbursement codes were used to capture cases with palliative conditions. The prevalence was ascertained for the year 2015. The incidence was calculated for patients without documented palliative care services in the year before the observation period. The Kaplan-Meier method was used to analyze the 1-year all-

Results The incidence rate of palliative conditions was 41.3 and 34.9 per 10,000 persons in women and men, respectively. The prevalence per 10,000 persons was 61.3 in women and 51.1 in men. The 1-year all-cause mortality among patients receiving their first palliative care treatment was $67.5 \%$. Mortality was lower in patients receiving general outpatient palliative care treatment (AAPV; 60.8\%) compared to patients receiving specialized outpatient palliative care treatment (SAPV; 86.1\%) or inpatient palliative care treatment $(90.6 \%)$. Within the first 30 days, mortality was particularly high $(\sim 43.0 \%)$.

Conclusions In Germany, more than 400,000 patients per year receive palliative care treatment, which is lower compared to estimates of the number of persons with a potential need for palliative care. This gap was observed particularly in younger to middle-aged

H. Gothe

holger.gothe@iges.com

1 IGES Institut GmbH, Friedrichstraße 180, 10117 Berlin, Germany

2 Department of Health Sciences / Public Health, Faculty of Medicine Carl Gustav Carus, TU Dresden, Löscherstraße 18, 01307 Dresden, Germany

3 Institute of Public Health, Medical Decision Making and Health Technology Assessment, Department of Public Health, Health Services Research and Health Technology Assessment, UMIT University for Health Sciences, Medical Informatics and Technology, Eduard-Wallnoefer-Zentrum, 6060 Hall in Tirol, Austria

4 InGef - Institute for Applied Health Research Berlin, Spittelmarkt 12, 10117 Berlin, Germany individuals. The findings indicate a demand for methodologically sound studies to investigate the public health burden and to quantify the unmet need for palliative care in Germany.

Keywords Palliative care Claims data Incidence . Prevalence $\cdot$ Mortality $\cdot$ Germany

\section{Introduction}

With the epidemiological and demographic transition affecting modern societies, the need for medical care is changing. In particular, complex end-of-life care becomes more relevant with regard to multiple comorbidities and possible benefits at several stages of a condition (WHO 2011). In this context, palliative care is understood as care for patients with lifethreatening diseases and their families, to increase their quality of life. As cure for the underlying condition is unlikely, palliative care focuses on interdisciplinary approaches of pain and symptom management in the sense of holistic care (WHO n. d.). In Germany, an increasing demand of palliative 
care is to be expected due to the demographic transition (Simon et al. 2012), as well as a realization of the patients' preference with regard to the place of death. While studies show that most patients want to die at home (Escobar Pinzon et al. 2013; Gomes et al. 2012), only one third does so (Escobar Pinzon et al. 2013; Sauer et al. 2015).

Re-elaborating of health care services is deemed to be necessary to meet the complex requirements of end-of-life care, in order to achieve a level of care that is of high quality and appropriate to matching people's needs (Ewers and Schaeffer 2007). Many of the current deficits are caused by inadequate structuring of care processes (Schneider et al. 2006). To meet the expected increase in demand for palliative care services, the infrastructure for palliative care in Germany comprises several concepts. Hospitalized patients may receive palliative care in specialized hospital wards or, with the help of palliative consultation services, be enabled to return home (Prütz and Sass 2017). Outpatient services include general outpatient services (Allgemeine Ambulante Palliativ-Versorgung, AAPV) provided by general practitioners or nursing services, as well as specialized outpatient palliative care (Spezialisierte Ambulante Palliativ-Versorgung, SAPV) for patients with complex needs, provided by interdisciplinary specialized teams (Prütz and Sass 2017). Office-based physicians, however, still describe the outpatient health care situation as insufficient. The best cooperation is seen with caregivers, but cooperation with psycho-social care providers should be improved. Studies are requested that focus on the collection of longitudinal data for more comprehensive insight (Prenzler et al. 2011).

Due to the fragmented system of care delivery with its accompanying databases, there are hardly any comprehensive statistics about the present use of and the future demand for palliative care services in Germany. The future demand may manifest itself in patients with those (co)morbidity conditions which may also request palliative care treatment. For such circumstances the term palliative care sensitive conditions seems to be suitable. Information on the demand for palliative care under definite circumstances would supply relevant indicators to determine an unmet medical need and to foster health care planning purposes. It would, therefore, be of considerable public health interest. A combination of aggregated data from different care settings (i.e., inpatient and outpatient) would entail several limitations, e.g., double counting of cases as described in a comprehensive overview of the data sources available for each palliative care delivery setting in Germany (Prütz and Sass 2017). Thus, information on the actual use of palliative care services in Germany is scarce.

\section{Aim}

The aim of this study was to estimate the incidence and prevalence of palliative care conditions, to characterize the comorbidity profile of patients receiving palliative care treatment, and to analyze the 1-year all-cause mortality of patients with a first palliative care treatment.

\section{Subjects and methods}

\section{Data source}

A retrospective real-world data (RWD) analysis was performed, based on statutory health insurance (SHI) claims data (cf. Swart et al. 2014). Source of data was the InGef (Institute for Applied Health Research Berlin) Research Database, which is an anonymized claims database comprising longitudinal data from approximately 6.7 million persons insured in one of the 70 German SHI companies covered by InGef. For the purpose of this analysis, the InGef Research Database was condensed to a sample of approximately 4 million subjects, which is considered representative of the German population in terms of age and sex, and shows high external validity regarding overall measures of morbidity, mortality, and drug use as described elsewhere (Andersohn and Walker 2016). In brief, the InGef Research Database contains sociodemographic information such as age, sex, and the region of residence. In addition, the database gives information on hospitalizations, outpatient physician visits, and outpatient drug prescriptions. The hospital data comprises information on the date of admission and discharge, the reason for discharge, and diagnostic and therapeutic procedures with the exact date, as well as diagnoses which can be distinguished in hospital main discharge diagnoses and secondary diagnoses. The outpatient data cover diagnostic and therapeutic information. Outpatient diagnoses can be distinguished into confirmed diagnoses, suspected diagnoses, status post diagnoses, and diagnoses ruled out. Inpatient and outpatient diagnoses are coded according to the German modification of the International Classification of Diseases 10th Revision (ICD-10-GM). Data on outpatient prescription of reimbursed drugs comprise information on the date of prescription and dispensation as well as the pharmaceutical reference numbers. Based on a pharmaceutical reference database information on the anatomicaltherapeutic-chemical code (ATC code), the defined daily dose (DDD), the package size as well as the strength and formulation of the drug can be linked for each dispensed drug. Furthermore, information on the specialty of care-providing physicians can be obtained from the database (Andersohn and Walker 2016; Ohlmeier et al. 2018).

\section{Study design}

The study was conducted according to the Good Practice of Secondary Data Analysis (GPS) recommendations (Swart et al. 2015). To estimate the prevalence of palliative care 
conditions, a cross-sectional study was carried out. A retrospective cohort design was used to estimate the incidence and 1 -year all-cause mortality of palliative care conditions. The analyses were based on the years 2014 to 2016, since information on relevant palliative care services were not comprised in the data prior to 2014, and since 2016 was the most recent data year available at the time the study was carried out.

\section{Study population}

Patients were included in the overall study population if they had continuous insurance coverage during 2014 and at least 1 day of insurance coverage in 2015. In the subpopulation of patients with an incident case with reimbursement claims for palliative care in 2015, the subsequent 1-year all-cause mortality was analyzed (identification see below).

\section{Identification of palliative care conditions}

The documentation of palliative care treatment is possible in both the outpatient and inpatient setting. Therefore, a palliative care condition was assumed, if one of the following criteria was met:

- Documentation of general outpatient palliative care treatment (AAPV) based on the following codes for the reimbursement of outpatient procedures (EBM-codes): 04370, 04371, 04372, 04373, 03370, 03371, 03372, 03373.

- Documentation of specific outpatient palliative care treatment (SAPV) based on the following codes for the reimbursement of outpatient procedures (EBM-codes): 01425, 01426.

- Documentation of inpatient palliative care treatment based on the following codes for the reimbursement of inpatient procedures (OPS-codes): 8-982, 8-98e. The OPS-code 8$98 \mathrm{~h}$ was not considered, since it was introduced in 2017.

An incident palliative care condition was assumed in case of an absence of the abovementioned codes on palliative care treatment in 2014. The first documented palliative care treatment in 2015 was then defined as the start of the palliative care treatment.

\section{Identification of deaths}

Deaths in the 365-day observation period after the start of the palliative care treatment were identified in the dataset, if the reason for the end of the insurance period was "death". The date of death was defined as the end date of the insurance period which indicated death. Validation studies of German claims data suggest an accurate and valid documentation of the status of death as well as the date of death (Ohlmeier et al. 2016; Ohlmeier et al. 2015).

\section{Patient comorbidity}

Hospital main or secondary discharge diagnoses and confirmed outpatient diagnoses were considered in order to calculate the frequency of pre-specified diseases and to analyze the general comorbidity via Elixhauser comorbidity score (ECS) (Quan et al. 2005) in patients with palliative care conditions. One documented diagnosis in 2015 was sufficient to be identified as suffering from the specific comorbidity.

\section{Statistical analyses}

The incidence of cases with reimbursement claims for palliative care conditions in 2015 was calculated by dividing the number of patients with an incident palliative care condition by the number of subjects in the study population who had no cases with reimbursement claims for palliative care treatment in 2014. Incidence rates were given per 10,000 persons, stratified by sex and age. The prevalence of palliative care conditions in 2015 was calculated by dividing the number of patients with prevalent reimbursement codes for a palliative care condition by the number of subjects in the study population. The prevalence rates were also stratified by sex and age, referring to 10,000 persons. The number of subjects with reimbursement codes for a palliative care condition was extrapolated to the German population based on the age and sex distribution of the German population. The 1-year allcause mortality of patients with an incident reimbursement code for a palliative care condition was calculated using the Kaplan-Meier method stratified by type of initial palliative care treatment. Differences between the types of treatment were evaluated using the log rank test $(p<0.05)$.

\section{Results}

\section{Patient characteristics}

In total, $n=14,522$ patients with an incident reimbursement code for a palliative care condition in 2015 were identified. Of those, $55.3 \%$ were female and $44.7 \%$ were male (Table 1 ). The mean age of patients with an incident reimbursement code for a palliative care condition was 76.9 [standard deviation (SD): 13.4] and was slightly higher in women than in men. The majority of the patients received AAPV as the initial palliative care treatment $(76.1 \%)$, whereas the inpatient complex palliative treatment and the SAPV were rarely observed as an initial palliative care treatment $(14.6 \%$ and $9.3 \%$ respectively). In men, the proportion of patients with inpatient complex palliative treatment or SAPV as the initial treatment was marginally higher compared to women.

A malignant neoplasm was observed in $56.4 \%$ of all patients with an incident reimbursement code for a palliative 
Table 1 Characteristics of patients with an incident palliative care condition in 2015

\begin{tabular}{|c|c|c|c|c|c|c|}
\hline & \multicolumn{2}{|c|}{ Women $(n=8031)$} & \multicolumn{2}{|c|}{$\operatorname{Men}(n=6491)$} & \multicolumn{2}{|c|}{ All $(n=14,522)$} \\
\hline & $N$ & $\%$ & $N$ & $\%$ & $N$ & $\%$ \\
\hline \multicolumn{7}{|l|}{ Age } \\
\hline $0-9$ years & 16 & $0.2 \%$ & 13 & $0.2 \%$ & 29 & $0.2 \%$ \\
\hline 10-19 years & 19 & $0.2 \%$ & 15 & $0.2 \%$ & 34 & $0.2 \%$ \\
\hline 20-29 years & 19 & $0.2 \%$ & 20 & $0.3 \%$ & 39 & $0.3 \%$ \\
\hline $30-39$ years & 45 & $0.6 \%$ & 46 & $0.7 \%$ & 91 & $0.6 \%$ \\
\hline $40-49$ years & 182 & $2.3 \%$ & 139 & $2.1 \%$ & 321 & $2.2 \%$ \\
\hline $50-59$ years & 534 & $6.6 \%$ & 510 & $7.9 \%$ & 1044 & $7.2 \%$ \\
\hline $60-69$ years & 882 & $11.0 \%$ & 1088 & $16.8 \%$ & 1970 & $13.6 \%$ \\
\hline 70-79 years & 1812 & $22.6 \%$ & 2139 & $33.0 \%$ & 3951 & $27.2 \%$ \\
\hline $80-89$ years & 2803 & $34.9 \%$ & 1982 & $30.5 \%$ & 4785 & $33.0 \%$ \\
\hline$>90$ years & 1719 & $21.4 \%$ & 539 & $8.3 \%$ & 2258 & $15.5 \%$ \\
\hline All & 8031 & $100.0 \%$ & 6491 & $100.0 \%$ & 14,522 & $100.0 \%$ \\
\hline Mean age (mean, SD) & 78.7 & 13.8 & 74.7 & 12.7 & 76.9 & 13.4 \\
\hline \multicolumn{7}{|l|}{ Sex } \\
\hline Female & 8031 & $100.0 \%$ & - & - & 8031 & $55.3 \%$ \\
\hline Male & - & - & 6491 & $100.0 \%$ & 6491 & $44.7 \%$ \\
\hline \multicolumn{7}{|l|}{ Initial palliative care treatment } \\
\hline General outpatient palliative care (AAPV) & 6265 & $78.0 \%$ & 4782 & $73.7 \%$ & 11,047 & $76.1 \%$ \\
\hline Specialized outpatient palliative care (SAPV) & 690 & $8.6 \%$ & 658 & $10.1 \%$ & 1348 & $9.3 \%$ \\
\hline Inpatient complex palliative treatment & 1076 & $13.4 \%$ & 1051 & $16.2 \%$ & 2127 & $14.6 \%$ \\
\hline
\end{tabular}

$S D$ : Standard deviation

care condition; the prevalence of malignant neoplasms was higher in men $(65.0 \%)$ than in women $(49.5 \%)$ (Table 2). A metastatic state was present in $29.4 \%$ of the patients, again with a higher prevalence in men $(34.3 \%)$ than in women (25.4\%). The given percentages refer to the whole study population having cases with reimbursement claims for palliative care. The most frequent localizations in both sexes were malignant neoplasms of digestive organs, with a prevalence of $16.8 \%$, and malignant neoplasms of respiratory and intrathoracic organs, with a prevalence of $10.5 \%$. According to expectations, malignant neoplasms of the breast were a frequently observed comorbidity in women $(14.5 \%)$, whereas the prevalence of malignant neoplasms of genital organs was high in men $(15.2 \%)$.

\section{Incidence of cases with reimbursement codes for palliative care conditions}

In 2015, the incidence of cases with reimbursement codes for palliative care conditions was 38.1 per 10,000 persons on average, and was higher in women than in men (41.3 and 34.9 per 10,000 persons respectively). The incidence increased with advancing age, and doubled from every age group to the next higher one. The incidence was highest in subjects aged 90 years or older (546.0 per 10,000 persons, Table 3). The age-stratified incidence of cases with reimbursement codes for palliative care conditions was higher in men than in women in most of the defined age categories. Taking into account the age structure of the German population, the extrapolation of the observed incidence estimates results in $n=153,985$ women and $n=125,185$ men with a first occurrence of a case with a reimbursement code for palliative care condition in 2015.

\section{Prevalence of cases with reimbursement codes for palliative care conditions}

The prevalence of cases with reimbursement codes for palliative care conditions was 56.3 per 10,000 persons, and was also higher in women than in men (61.3 and 51.1 per 10,000 persons, respectively). Similarly to the incidence, the prevalence increased with advancing age, and doubled from every age group to the next higher one. The prevalence was highest in persons aged 90 years or older (762.6 per 10,000 persons, Table 4). The extrapolation of the age-stratified prevalence estimates to the German population resulted in more than 400,000 individuals (over 220,000 women and 180,000 men) with palliative care sensitive conditions in 2015. 
Table 2 General and specific comorbidity of patients with an incident palliative care condition in 2015

\begin{tabular}{|c|c|c|c|c|c|c|}
\hline & \multicolumn{2}{|c|}{ Women $(n=8031)$} & \multicolumn{2}{|c|}{$\operatorname{Men}(n=6491)$} & \multicolumn{2}{|c|}{ All $(n=14,522)$} \\
\hline & $N$ & $\%$ & $N$ & $\%$ & $N$ & $\%$ \\
\hline \multicolumn{7}{|l|}{ Elixhauser comorbidity score } \\
\hline 0 diseases & 111 & $1.4 \%$ & 82 & $1.3 \%$ & 193 & $1.3 \%$ \\
\hline 1 disease & 266 & $3.3 \%$ & 180 & $2.8 \%$ & 446 & $3.1 \%$ \\
\hline 2 diseases & 525 & $6.5 \%$ & 333 & $5.1 \%$ & 858 & $5.9 \%$ \\
\hline 3 diseases & 757 & $9.4 \%$ & 503 & $7.7 \%$ & 1260 & $8.7 \%$ \\
\hline 4 diseases & 902 & $11.2 \%$ & 671 & $10.3 \%$ & 1573 & $10.8 \%$ \\
\hline 5 diseases & 989 & $12.3 \%$ & 753 & $11.6 \%$ & 1742 & $12.0 \%$ \\
\hline$>6$ diseases & 4481 & $55.8 \%$ & 3969 & $61.1 \%$ & 8450 & $58.2 \%$ \\
\hline Mean number of diseases (mean, SD) & 6.4 & 3.2 & 6.8 & 3.2 & 6.6 & 3.2 \\
\hline \multicolumn{7}{|l|}{ Specific oncological comorbidity (localization) } \\
\hline Any malignant neoplasm & 3974 & $49.5 \%$ & 4216 & $65.0 \%$ & 8190 & $56.4 \%$ \\
\hline Lip, oral cavity and pharynx & 97 & $1.2 \%$ & 213 & $3.3 \%$ & 310 & $2.1 \%$ \\
\hline Digestive organs & 1102 & $13.7 \%$ & 1331 & $20.5 \%$ & 2433 & $16.8 \%$ \\
\hline Respiratory and intrathoracic organs & 598 & $7.4 \%$ & 929 & $14.3 \%$ & 1527 & $10.5 \%$ \\
\hline Bone and articular cartilage & 45 & $0.6 \%$ & 36 & $0.6 \%$ & 81 & $0.6 \%$ \\
\hline Melanoma and other malignant neoplasms of skin & 478 & $6.0 \%$ & 579 & $8.9 \%$ & 1057 & $7.3 \%$ \\
\hline Mesothelial and soft tissue & 161 & $2.0 \%$ & 159 & $2.4 \%$ & 320 & $2.2 \%$ \\
\hline Breast & 1166 & $14.5 \%$ & 13 & $0.2 \%$ & 1179 & $8.1 \%$ \\
\hline Female genital organs & 543 & $6.8 \%$ & $<5$ & - & - & - \\
\hline Male genital organs & $<5$ & - & 986 & $15.2 \%$ & - & - \\
\hline Urinary tract & 254 & $3.2 \%$ & 600 & $9.2 \%$ & 854 & $5.9 \%$ \\
\hline Eye, brain and other parts of central nervous system & 123 & $1.5 \%$ & 143 & $2.2 \%$ & 266 & $1.8 \%$ \\
\hline Thyroid and other endocrine glands & 73 & $0.9 \%$ & 61 & $0.9 \%$ & 134 & $0.9 \%$ \\
\hline Hodgkin lymphoma & 19 & $0.2 \%$ & 23 & $0.4 \%$ & 42 & $0.3 \%$ \\
\hline Non-Hodgkin lymphoma & 145 & $1.8 \%$ & 192 & $3.0 \%$ & 337 & $2.3 \%$ \\
\hline Leukaemia & 110 & $1.4 \%$ & 178 & $2.7 \%$ & 288 & $2.0 \%$ \\
\hline Secondary neoplasms & 2037 & $25.4 \%$ & 2228 & $34.3 \%$ & 4265 & $29.4 \%$ \\
\hline Other types of cancer & 628 & $7.8 \%$ & 714 & $11.0 \%$ & 1342 & $9.2 \%$ \\
\hline \multicolumn{7}{|l|}{ Specific non-oncological comorbidity } \\
\hline Heart failure & 2950 & $36.7 \%$ & 2148 & $33.1 \%$ & 5098 & $35.1 \%$ \\
\hline Kidney failure & 2531 & $31.5 \%$ & 2166 & $33.4 \%$ & 4697 & $32.3 \%$ \\
\hline Respiratory failure & 1005 & $12.5 \%$ & 1083 & $16.7 \%$ & 2088 & $14.4 \%$ \\
\hline Liver disease & 1258 & $15.7 \%$ & 1408 & $21.7 \%$ & 2666 & $18.4 \%$ \\
\hline Chronic obstructive pulmonary disease & 1318 & $16.4 \%$ & 1516 & $23.4 \%$ & 2834 & $19.5 \%$ \\
\hline Depression & 3095 & $38.5 \%$ & 1544 & $23.8 \%$ & 4639 & $31.9 \%$ \\
\hline
\end{tabular}

Numbers which are too low $(<5)$ or might allow indirect calculability of too low case numbers cannot be displayed due to data protection reasons

$S D$ : Standard deviation

\section{One-year all-cause mortality in patients with incident cases with reimbursement codes for palliative care conditions}

As stated in the Methods section (subsection Study population) this study determines the 1-year all-cause mortality in patients with incident occurrence of reimbursement codes for palliative care conditions during the 1-year period subsequent to the index date. For instance, if someone was prescribed SAPV in November 2014 and died in October 2015 , this case was included in the 1-year all-cause mortality. The 1-year all-cause mortality of the 14,522 patients with an incident occurrence of reimbursement codes for palliative care conditions was $67.5 \%$ and was slightly higher in men (69.1\%) than in women $(66.2 \%)$. Mortality was highest in the first month after initiation of palliative care treatment $(35.0 \% 30$ - 
Table 3 Incidence of palliative care conditions in 2015 stratified by age and sex

\begin{tabular}{|c|c|c|c|c|c|c|c|c|c|c|c|c|}
\hline \multirow[b]{2}{*}{ Age } & \multicolumn{4}{|c|}{ Women $(n=8031)$} & \multicolumn{4}{|c|}{$\operatorname{Men}(n=6491)$} & \multicolumn{4}{|c|}{ All $(n=14,522)$} \\
\hline & $\begin{array}{l}N \\
\text { population }\end{array}$ & $\begin{array}{l}n \\
\text { cases }\end{array}$ & $\begin{array}{l}\text { Incidence } \\
\text { per } 10,000 \\
\text { persons }\end{array}$ & $95 \% \mathrm{CI}$ & $\begin{array}{l}N \\
\text { population }\end{array}$ & $\begin{array}{l}n \\
\text { cases }\end{array}$ & $\begin{array}{l}\text { Incidence } \\
\text { per } 10,000 \\
\text { persons }\end{array}$ & $95 \% \mathrm{CI}$ & $\begin{array}{l}N \\
\text { population }\end{array}$ & $\begin{array}{l}n \\
\text { cases }\end{array}$ & $\begin{array}{l}\text { Incidence } \\
\text { per } 10,000 \\
\text { persons }\end{array}$ & $95 \% \mathrm{CI}$ \\
\hline $0-9$ years & 124,535 & 16 & 1.3 & $0.7-1.9$ & 131,220 & 13 & 1.0 & $0.5-1.5$ & 255,755 & 29 & 1.1 & $0.7-1.5$ \\
\hline $10-19$ years & 179,177 & 19 & 1.1 & $0.6-1.5$ & 189,376 & 15 & 0.8 & $0.4-1.2$ & 368,553 & 34 & 0.9 & $0.6-1.2$ \\
\hline $20-29$ years & 202,284 & 19 & 0.9 & $0.5-1.4$ & 207,964 & 20 & 1.0 & $0.5-1.4$ & 410,248 & 39 & 1.0 & $0.7-1.2$ \\
\hline $30-39$ years & 229,943 & 45 & 2.0 & $1.4-2.5$ & 233,035 & 46 & 2.0 & $1.4-2.5$ & 462,978 & 91 & 2.0 & $1.6-2.4$ \\
\hline $40-49$ years & 271,988 & 182 & 6.7 & $5.7-7.7$ & 278,389 & 139 & 5.0 & $4.2-5.8$ & 550,377 & 321 & 5.8 & $5.2-6.5$ \\
\hline $50-59$ years & 311,805 & 534 & 17.1 & $15.7-18.6$ & 316,200 & 510 & 16.1 & $14.7-17.5$ & 628,005 & 1044 & 16.6 & $15.6-17.6$ \\
\hline $60-69$ years & 238,399 & 882 & 37.0 & $34.6-39.4$ & 226,143 & 1088 & 48.1 & $45.3-51.0$ & 464,542 & 1970 & 42.4 & $40.5-44.3$ \\
\hline $70-79$ years & 224,534 & 1812 & 80.7 & $77.0-84.4$ & 187,828 & 2139 & 113.9 & $109.1-118.7$ & 412,362 & 3951 & 95.8 & $92.8-98.8$ \\
\hline $80-89$ years & 131,125 & 2803 & 213.8 & $205.9-221.6$ & 82,074 & 1982 & 241.5 & $231.0-252.0$ & 213,199 & 4785 & 224.4 & $218.2-230.7$ \\
\hline$\geq 90$ years & 31,749 & 1719 & 541.4 & $516.5-566.3$ & 9609 & 539 & 560.9 & $514.9-606.9$ & 41,358 & 2258 & 546.0 & $524.1-567.9$ \\
\hline All & $1,945,539$ & 8031 & 41.3 & $40.4-42.2$ & $1,861,838$ & 6491 & 34.9 & $34.0-35.7$ & $3,807,377$ & 14,522 & 38.1 & $37.5-38.8$ \\
\hline
\end{tabular}

$C I$ : confidence interval

day mortality). The 1-year all-cause mortality was higher in patients with SAPV or inpatient complex palliative care ( $86.1 \%$ and $90.6 \%$ respectively) compared to patients with AAPV $(60.8 \%)$ as initial treatment (Fig. 1). The logrank test indicates significant differences in the mortality between AAPV and other types of treatment as initial palliative care treatment $(p<0.0001)$.

These mortality figures, related to palliative care, contrast against a 1-year all-cause mortality of approximately $1 \%(9.8$ per 1000 individuals) in the InGef Research Database of 4 million beneficiaries, which in turn is approximately $8 \%$ lower than the standardized mortality rate in Germany according to the Federal Statistical Office of Germany for the given year. Roughly 9800 of those 39,200 deceased in the InGef sample died with some sort of palliative care claims in the current or preceding year, which corresponds to approximately $25 \%$ of those dying.

\section{Discussion}

\section{Summary of findings}

Based on a representative German claims dataset, an incidence and prevalence of palliative care conditions of 38.1 and 56.3 per 10,000 persons, respectively, was observed. This corresponds to an annual number of 410.000 patients with a palliative care condition. Both incidence and prevalence increased sharply with advancing age. The 1-year allcause mortality in patients with an incident palliative care condition was $67.5 \%$, and was highest in the first thirty days after treatment initiation.

\section{Discussion of findings}

To our knowledge, there is hardly a similar study on the utilization of palliative care on a national level which would take into account the whole spectrum of palliative care-sensitive conditions. Instead, there are recent studies that use pre-selected indications, such as various types of cancer, to investigate the utilization of palliative care in the terminal life span (Blaschke et al. 2019). Other studies use death registration data to estimate the possible demand for palliative care by combining recorded (disease-specific) deaths with diagnoses defined as potentially in need of palliative care at the end of life. Initially, Rosenwax et al. (2005) defined deaths from all types of benign and malign cancer and six non-cancer-related diseases as potentially being in need of palliative care. Murtagh et al. (2014) argue that the method applied by Rosenwax et al. could underestimate the need for palliative care, and develop an adapted method which partially adds or excludes diagnostic codes based on their presumed relevance (Murtagh et al. 2014). For instance, they consider chronic conditions of the heart, liver, kidneys, and the circulatory system, as well as neurodegenerative diseases and dementia, whereas deceased subjects with benign neoplasms are neglected (Murtagh et al. 2014).

Some other studies in different countries, e.g., in Ireland (Kane et al. 2015) and in 12 other countries around the world (Morin et al. 2016), used analogue methods to estimate the number of individuals who potentially need palliative care. For Germany, Scholten et al. (2016) used the Rosenwax method and the Murtagh method to determine the number of deceased individuals who in the year 2013 may have been in need for palliative care. Their estimation resulted in a total number of deaths of $n=363,689$ (40.7\% of all deaths) and $n=697,281$ (78.0\% of all deaths) respectively.

With an extrapolated number of over 400,000 individuals of the entire German population being eligible for palliative care services each year, the estimated prevalence in our study is located between the estimates of both methods. The fact that, using the Rosenwax method, the calculated number for 


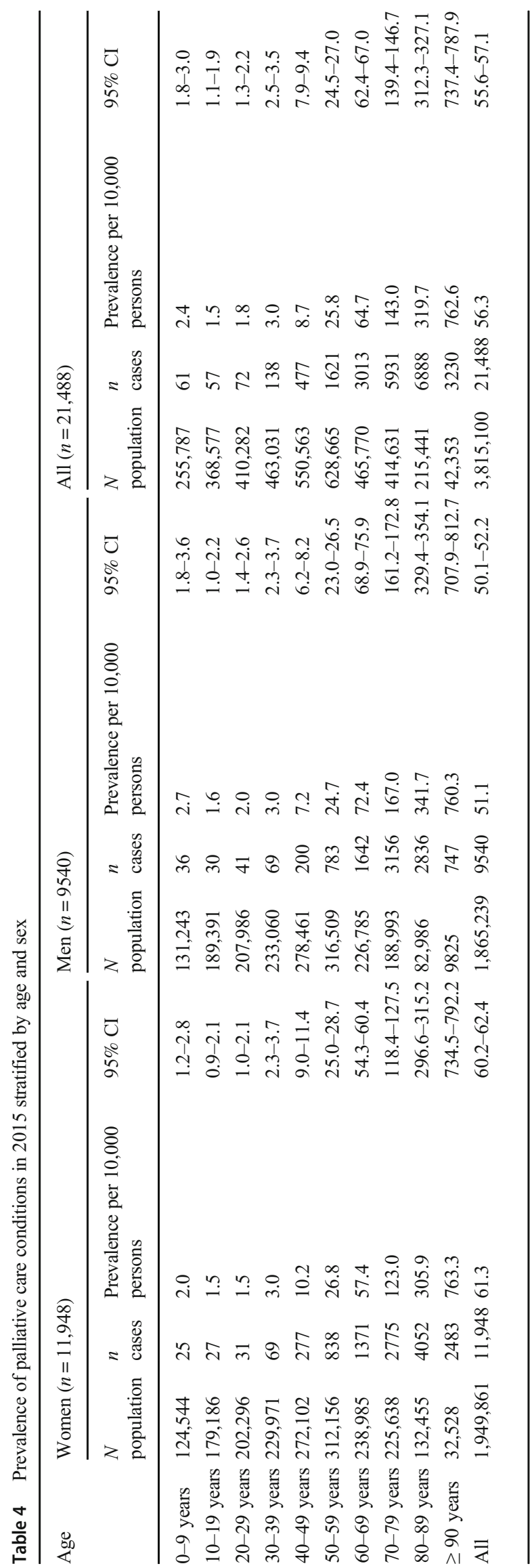


Fig. 1 Kaplan-Meier plot of the 1-year all-cause mortality of patients with incident palliative care condition stratified by type of initial palliative care treatment. Observations are called + Censored when the individuals did not experience the event of interest (i.e., survival) for the duration of the study

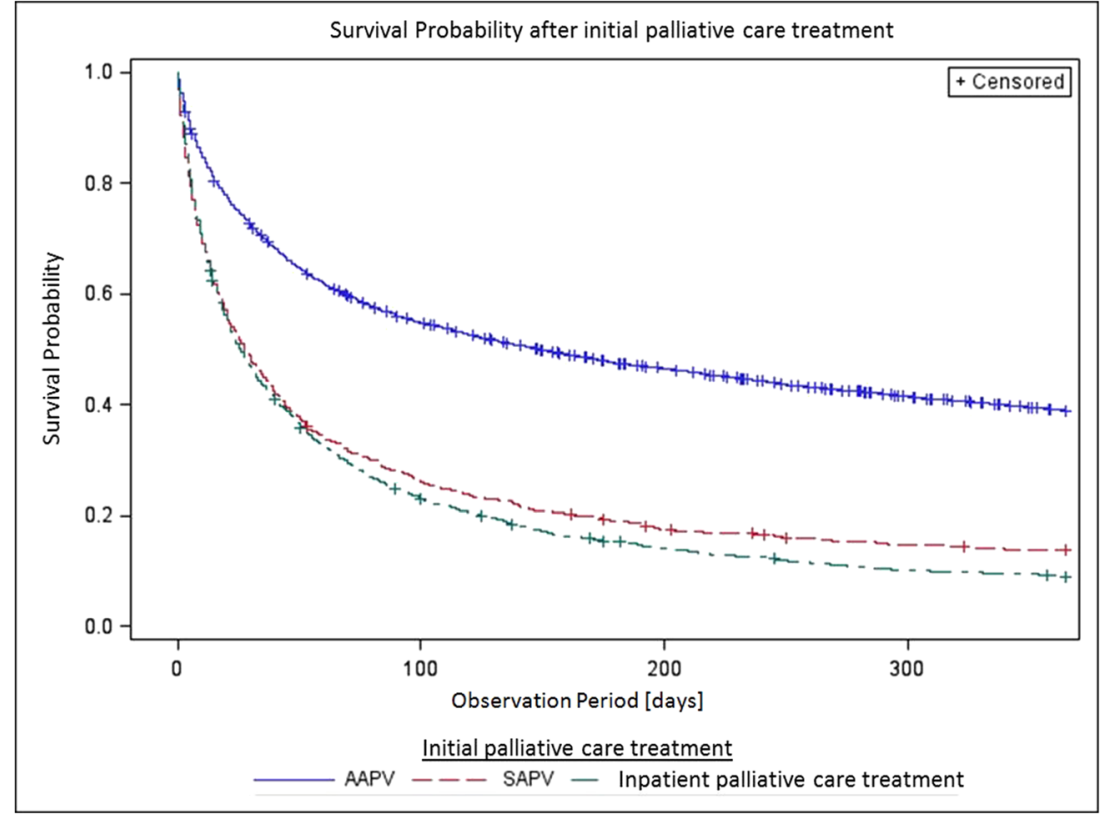

potential need lies below the actual utilization figures for palliative care, would imply either that the Rosenwax method indeed underestimates the potential need, for instance by neglecting the need of patients with chronic diseases, or that the utilization of palliative care in Germany is already higher than the demand. This, however, is unlikely, because there is evidence for the lack in the provision of palliative care, especially in rural areas (Radbruch et al. 2015).

In contrast to Scholten et al. (2016), who determine the potential need for palliative care with various estimates, our study examines the present utilization of palliative care from a bottom-up perspective. Therefore, it is not surprising that Scholten's estimate with the Murtagh method exceeds the prevalence found in our study. However, a gap between the use and the potential need seems to be noticeable, considering an estimated need that exceeds the actual utilization figures. Without having applied mathematical methods to prove this impression, the trends in the upward-sloping utilization figures over the various age groups appear to be rather similar: While the potential demand rises faster from 30 years onwards (Scholten et al. 2016), the utilization increases sharply in the age group of 70 years and above. This suggests an unmet need for palliative care, especially in the middle-aged patient group. A reason for the comparatively high unmet medical need for palliative care in middle-aged persons could lie in the predominance of curative treatment attempts for life-threatening diseases, although palliative care would already be indicated. With regard to this hypothesis, several studies suggest that earlier integration of palliative care, e.g., in parallel to curative treatment approaches, may be beneficial concerning quality of life (Temel et al. 2010; Zimmermann et al. 2014) and costs (May et al. 2015, 2018).

\section{Strengths and limitations}

The main strength of this study is the large, unselected, and supraregional sample allowing robust estimations of the incidence, prevalence, and 1-year all-cause mortality of palliative care conditions. Further, recall and selection bias, both being a considerable methodological challenge to health services research in end-of-life studies, could be avoided since our study was based on routine claims data and did not depend on patients' recall abilities or the willingness to participate.

The identification mechanism applied in this study is guided by the idea that a palliative care condition is given in cases where specific reimbursement claims are coded. This may occur in situations, (a) in which a care-giver sees the indication for a palliative care intervention, and/or (b) where an opportunity to bill such interventions is given. With this type of capturing algorithms, it cannot be excluded that actually existing, but not yet recognized situations with palliative care demands remain undetected. On the other hand, considering the level of specifity of the available reimbursement codes, it can be assumed that in the presence of an encoded claim for a palliative care intervention, a related palliative condition is factually existent. One can hardly imagine that palliative care services are provided without claiming the designated reimbursement code.

Although all available information can be linked on a person-individual level, the specific diagnoses triggering the utilization of care services in the sense of actual indications cannot be identified. Therefore, it was not possible to analyze, for instance, the distribution of diseases leading to the initiation of palliative care treatments. Furthermore, because of restrictions due to data safety requirements imposed by the SHI 
data provider, it was not feasible to perform in-depth analyses of the case development over time, to observe case histories on an individual level, or to assess a potential cross-over between general and specialized palliative care treatment.

\section{Conclusion}

This study provides authentic insight into the utilization of palliative care services in Germany. The use of palliative care services is lower than the potential need estimated by other studies, which, however, are of heterogeneous quality and varying scientific rigor. On the one hand, the supposed gap between the actual utilization level and the estimated need might be due to methodological reasons. On the other hand, this gap points towards an unmet medical need for palliative care treatment, particularly in younger and middle-aged individuals. The study at hand indicates a considerable demand for methodologically sound and well-arranged studies to quantify the Public Health burden of palliative conditions in Germany. Findings such as ours, together with an upcoming evaluation study on specific types of palliative care (Freytag et al. 2019), should be taken into account in the context of health care planning.

Funding Information This study was funded by Sanofi Aventis Germany $\mathrm{GmbH}$. The funding source had no impact on study design, analysis, and interpretation of data, on the writing of the manuscript, and on the decision to submit the manuscript for publication. Open Access funding provided by Projekt DEAL.

\section{Compliance with ethical standards}

Conflict of interest Carolin Brinkmann, Holger Gothe and Christoph Ohlmeier have received research grants from Sanofi Aventis Germany $\mathrm{GmbH}$. Niklas Schmedt and Jochen Walker declare that they have no conflict of interest.

Ethical statement In accordance with the Good Practice in Secondary Data Analysis (GPS), "Guideline 1: Ethics" (English version available at $\mathrm{https} / /$ www.dgepi.de/assets/Leitlinien-und-Empfehlungen/Practice-inSecondary-Data-Analysis.pdf) "secondary data analyses must be conducted in accordance with ethical principles and respect human dignity as well as human rights." It is, however, not mandatory to consult with an ethics committee, "if all the data protection provisions on pseudo-anonymization of all personal data are fulfilled ... and no link to primary data is intended" (Swart et al. 2015). Since the study at hand respects all these conditions, a vote of an ethics committee has not been requested.

Open Access This article is licensed under a Creative Commons Attribution 4.0 International License, which permits use, sharing, adaptation, distribution and reproduction in any medium or format, as long as you give appropriate credit to the original author(s) and the source, provide a link to the Creative Commons licence, and indicate if changes were made. The images or other third party material in this article are included in the article's Creative Commons licence, unless indicated otherwise in a credit line to the material. If material is not included in the article's Creative Commons licence and your intended use is not permitted by statutory regulation or exceeds the permitted use, you will need to obtain permission directly from the copyright holder. To view a copy of this licence, visit http://creativecommons.org/licenses/by/4.0/.

\section{References}

Andersohn F, Walker J (2016) Characteristics and external validity of the German Health Risk Institute (HRI) Database. Pharmacoepidemiol Drug Saf 25:106-109. https://doi.org/10.1002/pds.3895

Blaschke K, Hermes-Moll K, Lappe V, Ihle P, Baumann W, Schubert I (2019) Cancer patients and the last year of life: palliative care, hospitalization and place of death. Gesundheitswesen (First on-line: in German). https://doi.org/10.1055/a-0829-6604

Escobar Pinzon LC, Claus M, Perrar KM, Zepf KI, Letzel S, Weber M (2013) Dying with dementia: symptom burden, quality of care, and place of death. Dtsch Arztebl Int 110:195-202

Ewers M, Schaeffer D (2007) Dying in Germany — consequences of societal changes for palliative care and the health care system. J Public Health 15:457-465. https://doi.org/10.1007/s10389-0070099-z

Freytag A, Krause M, Bauer A, Ditscheid B, Jansky M, Krauss S, Lehmann T, Marschall U, Nauck F, Schneider W, Stichling K, Vollmar HC, Wedding U, Meißner W, SAVOIR Study Group (2019) Study protocol for a multi-methods study: SAVOIR — evaluation of specialized outpatient palliative care (SAPV) in Germany: outcomes, interactions, regional differences. BMC Palliative Care 18:12. https://doi.org/10.1186/s12904-019-0398-5

Gomes B, Higginson IJ, Calanzani N, Cohen J, Deliens L, Daveson BA, Bechinger-English D, Bausewein C, Ferreira PL, Toscani F, Meñaca A, Gysels M, Ceulemans L, Simon ST, Pasman HR, Albers G, Hall S, Murtagh FE, Haugen DF, Downing J, Koffman J, Pettenati F, Finetti S, Antunes B, Harding R, PRISMA (2012) Preferences for place of death if faced with advanced cancer: a population survey in England, Flanders, Germany, Italy, the Netherlands, Portugal and Spain. Ann Oncol 23:2006-2015. https://doi.org/10.1093/annonc/mdr602

Kane PM, Daveson BA, Ryan K, McQuillan R, Higginson IJ, Murtagh FE; BuildCARE (2015) The need for palliative care in Ireland: a population-based estimate of palliative care using routine mortality data, inclusive of nonmalignant conditions. J Pain Symptom Manag 49:726e1-733.e1. https://doi.org/10.1016/j.jpainsymman.2014.09. 011

May P, Garrido MM, Cassel JB, Kelley AS, Meier DE, Normand C, Smith TJ, Stefanis L, Morrison RS (2015) Prospective cohort study of hospital palliative care teams for inpatients with advanced cancer: earlier consultation is associated with larger cost-saving effect. J Clin Oncol 33(25):2745-2752. https://doi.org/10.1200/JCO.2014. 60.2334

May P, Normand C, Cassel JB, Del Fabbro E, Fine RL, Menz R, Morrison CA, Penrod JD, Robinson C, Morrison RS (2018) Economics of palliative care for hospitalized adults with serious Illness: a meta-analysis. JAMA Intern Med 178:820-829. https:// doi.org/10.1001/jamainternmed.2018.0750

Morin L, Aubry R, Frova L, MacLeod R, Wilson DM, Loucka M, Csikos A, Ruiz-Ramos M, Cardenas-Turanzas M, Rhee Y, Teno J, Öhlén J, Deliens L, Houttekier D, Cohen J (2016) Estimating the need for palliative care at the population level: a cross-national study in 12 countries. Palliat Med 31(6):526-536. https://doi.org/10.1177/ 0269216316671280

Murtagh FE, Bausewein C, Verne J, Groeneveld EI, Kaloki YE, Higginson IJ (2014) How many people need palliative care? A study 
developing and comparing methods for population-based estimates. Palliat Med 28:49-58. https://doi.org/10.1177/0269216313489367

Ohlmeier C, Langner I, Hillebrand K, Schmedt N, Mikolajczyk R, Riedel O, Garbe E (2015) Mortality in the German Pharmacological Research Database (GePaRD) compared to national data in Germany: results from a validation study. BMC Public Health 15: 570. https://doi.org/10.1186/s12889-015-1943-7

Ohlmeier C, Langner I, Garbe E, Riedel O (2016) Validating mortality in the German Pharmacoepidemiological Research Database (GePaRD) against a mortality registry. Pharmacoepidemiol Drug Saf 25:778-784. https://doi.org/10.1002/pds.4005

Ohlmeier C, Leverkus F, Kloss S, Basic E, Bless HH (2018) Estimating the incidence of venous thromboembolism (VTE) using various types of routine data of the German healthcare system. Z Evid Fortbild Qual Gesundhwes139:46-52 [Article in German]. https:// doi.org/10.1016/j.zefq.2018.11.005

Prenzler A, von der Schulenburg JM MT, Theidel U, Montag T, MüllerBusch HC (2011) Aspects of outpatient palliative care in Germany - a survey among office-based physicians. J Public Health 19:155160. https://doi.org/10.1007/s10389-010-0360-8

Prütz F, Sass AC (2017) Data on palliative care in Germany: which data sources are available and what do they tell? Bundesgesundheitsbl 60:26-36. https://doi.org/10.1007/s00103-016-2483-8

Quan H, Sundararajan V, Halfon P, Fong A, Burnand B, Luthi JC, Saunders LD, Beck CA, Feasby TE, Ghali WA (2005) Coding algorithms for defining comorbidities in ICD-9-CM and ICD-10 administrative data. Med Care 43:1130-1139. https://doi.org/10.1097/ 01.mlr.0000182534.19832.83

Radbruch L, Andersohn F, Walker J (2015) Überversorgung kurativ Unterversorgung palliativ? Analyse ausgewählter Behandlungen am Lebensende. Palliativversorgung (Modul 3). In: Bertelsmann Stiftung (ed.) Faktencheck Gesundheit. Bertelsmann, Gütersloh

Rosenwax LK, McNamara B, Blackmore AM, Holman CDJ (2005) Estimating the size of a potential palliative care population. Palliat Med 19:556-562. https://doi.org/10.1191/0269216305pm1067oa

Sauer S, Müller R, Rothgang H (2015) Institutionalisiertes Sterben in Deutschland. Trends in der Sterbeortverteilung: zu Hause, Krankenhaus und Pflegeheim. Z Gerontol Geriat 48:169-175. https://doi.org/10.1007/s00391-013-0547-Z
Schneider N, Buser K, Amelung VE (2006) Improving palliative care in Germany: summative evaluation from experts' reports in Lower Saxony and Brandenburg. J Public Health 14:148-154. https://doi. org/10.1007/s10389-006-0034-8

Scholten N, Gunther AL, Pfaff H, Karbach U (2016) The size of the population potentially in need of palliative care in Germany - an estimation based on death registration data. BMC Palliative Care 15: 29. https://doi.org/10.1186/s12904-016-0099-2

Simon ST, Gomes B, Koeskeroglu P, Higginson IJ, Bausewein C (2012) Population, mortality and place of death in Germany (1950-2050) — implications for end-of-life care in the future. Public Health 126: 937-946. https://doi.org/10.1016/j.puhe.2012.06.014

Swart E, Ihle P, Gothe H, Matusiewicz D (2014) Routinedaten im Gesundheitswesen. Handbuch Sekundärdatenanalyse: Grundlagen, Methoden und Perspektiven. Verlag Hans Huber, Bern

Swart E, Gothe H, Geyer S, Jaunzeme J, Maier B, Grobe TG, Ihle P, on behalf of the German Society for Social Medicine and Prevention (DGSMP) and the German Society for Epidemiology (DGEpi) (2015) Good practice of secondary data analysis (GPS): guidelines and recommendations. Gesundheitswesen 77:120-126. https://doi. org/10.1055/s-0034-1396815

Temel JS, Greer JA, Muzikansky A, Gallagher ER, Admane S, Jackson VA, Dahlin CM, Blinderman CD, Jacobsen J, Pirl WF, Billings JA, Lynch TJ (2010) Early palliative care for patients with metastatic non-small-cell lung cancer. N Engl J Med 363(8):733-742. https:// doi.org/10.1056/NEJMoa1000678

WHO (2011) Palliative care for older people: better practices. World Health Organization, Copenhagen

WHO (n.d.) WHO Definition of Palliative Care. World Health Organization, Genevahttps://www.who.int/cancer/palliative/ definition/en/. Accessed 20.02.2019

Zimmermann C, Swami N, Krzyzanowska M, Hannon B, Leighl N, Oza A, Moore M, Rydall A, Rodin G, Tannock I, Donner A, Lo C (2014) Early palliative care for patients with advanced cancer: a clusterrandomised controlled trial. Lancet 383:1721-1730. https://doi. org/10.1016/s0140-6736(13)62416-2

Publisher's note Springer Nature remains neutral with regard to jurisdictional claims in published maps and institutional affiliations. 